Article

\title{
Water-Resistant Mechanoluminescent Electrospun Fabrics with Protected Sensitivity in Wet Condition via Plasma-Enhanced Chemical Vapor Deposition Process
}

\author{
Halim Lee ${ }^{1}$, Eunjin Cho ${ }^{1}$, Tomas Webbe Kerekes ${ }^{2}{ }^{\mathbb{D}}$, Seung Lee Kwon ${ }^{2}$, Gun Jin Yun ${ }^{2,3, *(1)}$ \\ and Jooyoun Kim 1,4,*(B) \\ 1 Department of Textiles, Merchandising and Fashion Design, Seoul National University, Seoul 08826, Korea; \\ hlee335@snu.ac.kr (H.L.); kkumda198@snu.ac.kr (E.C.) \\ 2 Department of Mechanical and Aerospace Engineering, Seoul National University, Seoul 08826, Korea; \\ tomaswebbe@gmail.com (T.W.K.); kwons17912@gmail.com (S.L.K.) \\ 3 Institute of Advanced Aerospace Technology, Seoul National University, Seoul 08826, Korea \\ 4 Research Institute of Human Ecology, Seoul National University, Seoul 08826, Korea \\ * Correspondence: gunjin.yun@snu.ac.kr (G.J.Y.); jkim256@snu.ac.kr (J.K.); Tel.: +82-2-880-8302 (G.J.Y.); \\ $+82-2-880-6846$ (J.K.)
}

Received: 9 July 2020; Accepted: 30 July 2020; Published: 31 July 2020

\begin{abstract}
Mechanoluminescence (ML), which emits light upon external mechanical stress, was applied to fibrous composites. Herein, ML particles were incorporated into poly(vinylidene fluoride) (PVDF) and polyacrylonitrile (PAN) electrospun webs to prepare ML/PVDF and ML/PAN composite fabrics. The produced fabrics were treated with $\mathrm{O}_{2}$ and $\mathrm{C}_{4} \mathrm{~F}_{8}$ plasma to modify the wetting properties, then the effects of composite wettability on the light-emitting response in dry and wet conditions were investigated. The light intensity was greatly decreased when the composite fabrics absorbed water. When the composites were hydrophobized by the $\mathrm{C}_{4} \mathrm{~F}_{8}$ plasma-enhanced chemical vapor deposition process, the original light intensity was protected in wet conditions, while maintaining the water vapor transmission rate. As the clothing material would be exposed to moisture in varied situations, the reduced ML sensitivity in wet conditions may limit the application of ML composite fabrics. The findings suggest a facile strategy to fabricate moisture-resistant, breathable mechanoluminescence composite fabrics.
\end{abstract}

Keywords: mechanoluminescence; electrospinning; water-resistant; plasma-enhanced chemical vapor deposition; sensor; smart textile

\section{Introduction}

The vigorous development of smart textiles has led to a new era of lifestyle. Countless smart textiles or devices are capable of monitoring and sensing natural phenomena around everyday life [1]. Most current smart textiles are powered by traditional rechargeable batteries which are large, heavy, and bulky; therefore, they are unsuitable to properly integrate with textiles, making the consolidation of a single system infeasible [2]. For this reason, there is a special interest to develop pliable and lightweight alternatives for electrical power generation and storage, such as flexible and elastic batteries [3-5], supercapacitors [6], photovoltaic [7], thermoelectric [8], and piezoelectric generators $[9,10]$. One way to fulfill the demands of mechanical sensors that work without batteries is by using mechanoluminescence. The development of mechanoluminescent (ML) materials has contributed to a broad source of multi-functional components with a wide range of applications in 
diverse fields [11,12]. It is well known that ML materials emit light when subjected to mechanical stress such as elastic-plastic deformation or even friction [13,14].

ML emits light according to a band theory, in which an electron gains energy from the external mechanical stress, where it goes to an excited state and then it releases the light when coming back to the ground state [15]. A distinct characteristic of ML appealed to researchers in materials science, leading to a wide scope of ML research [16]. Various types of ML with different components such as $\mathrm{SrAl}_{2} \mathrm{O}_{4}:\left(\mathrm{Eu}^{2+}, \mathrm{Dy}^{3+}\right), \mathrm{ZnS}: \mathrm{Mn}, \mathrm{Ca}_{2} \mathrm{MgSi}_{2} \mathrm{O}_{7}: \mathrm{Eu}$, and $\mathrm{CaZnOs}: \mathrm{Mn}$ have been observed and the investigation is still ongoing [17]. Among the earlier findings of $\mathrm{ML}$, the material used in the experiment was green-emitting phosphor of $\mathrm{SrAl}_{2} \mathrm{O}_{4}: \mathrm{Eu}^{2+}$ co-doped with $\mathrm{Dy}^{3+}$ (SAOED) which has been known as intense and long-lasting phosphorescence $[18,19]$. Recently, ML materials have caught the attention of researchers for application in a wide range of nondestructive evaluations [20-22] and for diverse types of mechano-optical devices [23,24]. The investigation has been conducted for the measurement and visualization of stress distribution of the SAOED-incorporated solids in the form of ML paint $[25,26]$; ML sensing film and adhesive [11,27-29]; and ML/epoxy composites [13,30-32].

When ML materials containing alkaline earth aluminates interact with water, the properties of both phosphorescence and mechanoluminescence can be deteriorated as the hydrolysis reaction of ML occurs. As clothing textiles can be exposed to the moist and sweaty environment, hydrolysis of ML in wet conditions puts a significant constraint on ML application to textiles. To prevent the hydrolysis of ML materials, several studies suggested introducing a water-resistant protection barrier for ML particles [33-35]. Such barrier materials often involve a complicated chemical procedure [35,36], and loss of flexibility and permeability, limiting the application to textile materials.

Herein, water-resistant yet breathable nonwoven fabrics with mechanoluminescence performance were proposed to detect mechanical stimulation, in consideration of the practical application in wet conditions. For this purpose, ML composite fabrics were fabricated by electrospinning of ML-incorporated PVDF and PAN fibers. The electrospinning technology used in this paper has a wide range of applications, which allows us to fabricate nanomaterials with little restriction on materials. With versatile process options, electrospinning is extending its capability of creating novel functional nonwovens $[37,38]$ and composite mats by combining functional materials with polymers [39,40]. This study employed a simple electrospinning process by dispersing the ML particles in the pre-spinning polymer solution to produce particle-incorporated composite webs.

The ML-incorporated PVDF electrospun web (ML/PVDF) and ML-incorporated PAN electrospun web (ML/PAN) were further modified to vary in wetting properties, either being hydrophilic or hydrophobic via a simple plasma process. The as-spun hydrophilized and hydrophobized composite fabrics of ML/PVDF and ML/PAN were compared for water add-on (\%) and wettability. The composites with different wettability were investigated for the ML performance both in dry and wet states. The breathability of ML composite fabrics was examined by measuring the water vapor transmission rate. In consideration of the textile application, the effects of composite thickness and layering on ML performance were investigated, and simulation was also conducted to interpret the results.

Ultimately, the study intends to suggest a facile strategy to fabricate the breathable composite fabrics of which performance is well maintained in wet conditions. The approach of this study is novel in that a simple technique of the plasma-enhanced chemical vapor deposition (PECVD) process was applied to composite fabrics to optimize ML performance in wet conditions. As PECVD produced a very thin layer of coating, the breathability of the composite fabric was maintained. The resulting material can be applied as a battery-free mechanoluminescent sensor in smart textiles.

\section{Materials and Methods}

\subsection{Materials}

Mechanoluminescence (strontium aluminate co-doped with europium ions and dysprosium ions, $\left.\mathrm{SrAl}_{2} \mathrm{O}_{4}:\left(\mathrm{Eu}^{2+}, \mathrm{Dy}^{3+}\right)\right)$ particles were purchased from Nemoto \& Co (Tokyo, Japan). Poly(vinylidene 
fluoride) (PVDF) resin $\left(M_{\mathrm{W}} 275,000\right)$ and polyacrylonitrile (PAN) resin $\left(M_{\mathrm{W}} 150,000\right)$ were purchased from Sigma-Aldrich (St. Louis, MO, USA). N, N-dimethylformamide (DMF) and acetone were bought from Daejung Chemicals (Siheung-si, Gyeonggi-do, South Korea). Calcium chloride, anhydrous, 96.0\% was purchased from Samchun Chemicals (Seoul, South Korea). Octafluorocyclobutane $\left(\mathrm{C}_{4} \mathrm{~F}_{8}\right)$ gas and oxygen gas $\left(\mathrm{O}_{2}\right)$ were purchased from Union Gas (Yongin-si, Gyeonggi-do, South Korea).

\subsection{Fabrication of $M L / P V D F$ and $M L / P A N$}

PVDF pellets were dissolved in a blend of (1:1 volume ratio) DMF and acetone, and the PVDF pre-spinning solution was prepared in $26 \%(w / v)$. ML powder was added to the respective pre-spinning solutions with $7.8 \%(w / v)$ of the solution. The ML in the pre-spinning solution was mixed in a vial using a magnetic stir bar at $60^{\circ} \mathrm{C}$ for $24 \mathrm{~h}$. The ML-containing pre-spinning solution was electrospun at the bias voltage of $10 \sim 12 \mathrm{kV}$ and the feeding rate of $4 \mathrm{~mL} / \mathrm{h}$. The electrospun fibers were collected to a rotating drum collector wrapped with paper foil $(180 \mathrm{rpm})$ at a distance of $15 \mathrm{~cm}$. The fiber was directly collected on the paper foil. The collected electrospun composite web was dried in an oven at $40^{\circ} \mathrm{C}$ for $24 \mathrm{~h}$. The thickness of the PVDF electrospun web was varied to $0.1,0.2$, and $0.4 \mathrm{~mm}$.

Polyacrylonitrile resin was mixed with DMF with $10 \%(w / v)$ to make a PAN pre-spinning solution. The ML was added to the pre-spinning solution in $7.8 \%(w / v)$ of the solution. The $w / v \%$ of ML in the composite web was adjusted to be the same for the ML/PVDF and ML/PAN webs. The ML-containing PAN solution was electrospun at $15 \sim 18 \mathrm{kV}$ with a $1 \mathrm{~mL} / \mathrm{h}$ feeding rate. The fibers were collected onto a rotating drum collector (at $200 \mathrm{rpm}$ ) from a distance of $15 \mathrm{~cm}$. The electrospinning process parameters were adjusted to produce beadless fibers in the consistent size range for the respective fibers, without clogging of the nozzle. Electrospinning was conducted under a temperature of $20 \pm 2{ }^{\circ} \mathrm{C}$ and relative humidity of $20 \pm 3 \%$ RH.

The surface chemistry of ML-incorporated electrospun fabric was modified by the plasma process. To attach the oxygen group to the composite surface, the composite fabric was subject to an $\mathrm{O}_{2}$ plasma treatment for $5 \mathrm{~min}$ at $200 \mathrm{~W}$ with $160 \mathrm{~cm}^{3} / \mathrm{min}$ in the plasma system (COVANCE, FemtoScience, Hwaseong, South Korea) [41]. To coat the surface with the fluorinated compound by the plasma-enhanced chemical vapor deposition (PECVD), the composite fabric was treated under $\mathrm{C}_{4} \mathrm{~F}_{8}$ gas for $25 \mathrm{~min}$ at $200 \mathrm{~W}$ with $100 \mathrm{~cm}^{3} / \mathrm{min}[42,43]$. The generated frequency of plasma was $50 \mathrm{kHz}$ in both $\mathrm{O}_{2}$ and $\mathrm{C}_{4} \mathrm{~F}_{8}$ plasma processes.

The wettability of the composite surface was examined via measurement of the static contact angles (CA) of water, using an optical tensiometer (Theta Lite, KSV Instruments Ltd., Espoo, Finland). For the CA measurement, a $3.4 \mu \mathrm{l}$ of water drop was placed on a surface, and the CA was measured within 5 secs after the deposition of a liquid drop. The measurement was done on at least five different locations of the sample surface.

\subsection{Measurement of Mechanoluminescence by the Ball Drop Test}

To measure the intensity of ML of the composites, a ball drop test was designed, where a $23 \mathrm{~g}$ spherical glass ball with a $2.5 \mathrm{~cm}$ radius was vertically dropped from a $20 \mathrm{~cm}$ distance from the composite surface (Figure 1a). The light intensity was measured when the fabric experienced instantaneous stress. For charging the photo energy to the samples, the composite samples were rested in the daylight condition for $1 \mathrm{~min}$ using standard lighting equipment (CO-204, Hanwon Soway Co., Seoul, South Korea). After $1 \mathrm{~min}$, the samples were rested in the darkroom for $5 \mathrm{~min}$ to discharge photo energy to control the maximum pixel intensity value (PIV) which reflects the light intensity of the sample. The maximum measurable PIV (unitless value) was 255, and the minimum was 0. Both charging time $(1 \mathrm{~min})$ and discharging time $(5 \mathrm{~min})$ were maintained the same to control the light intensity of ML composites. 

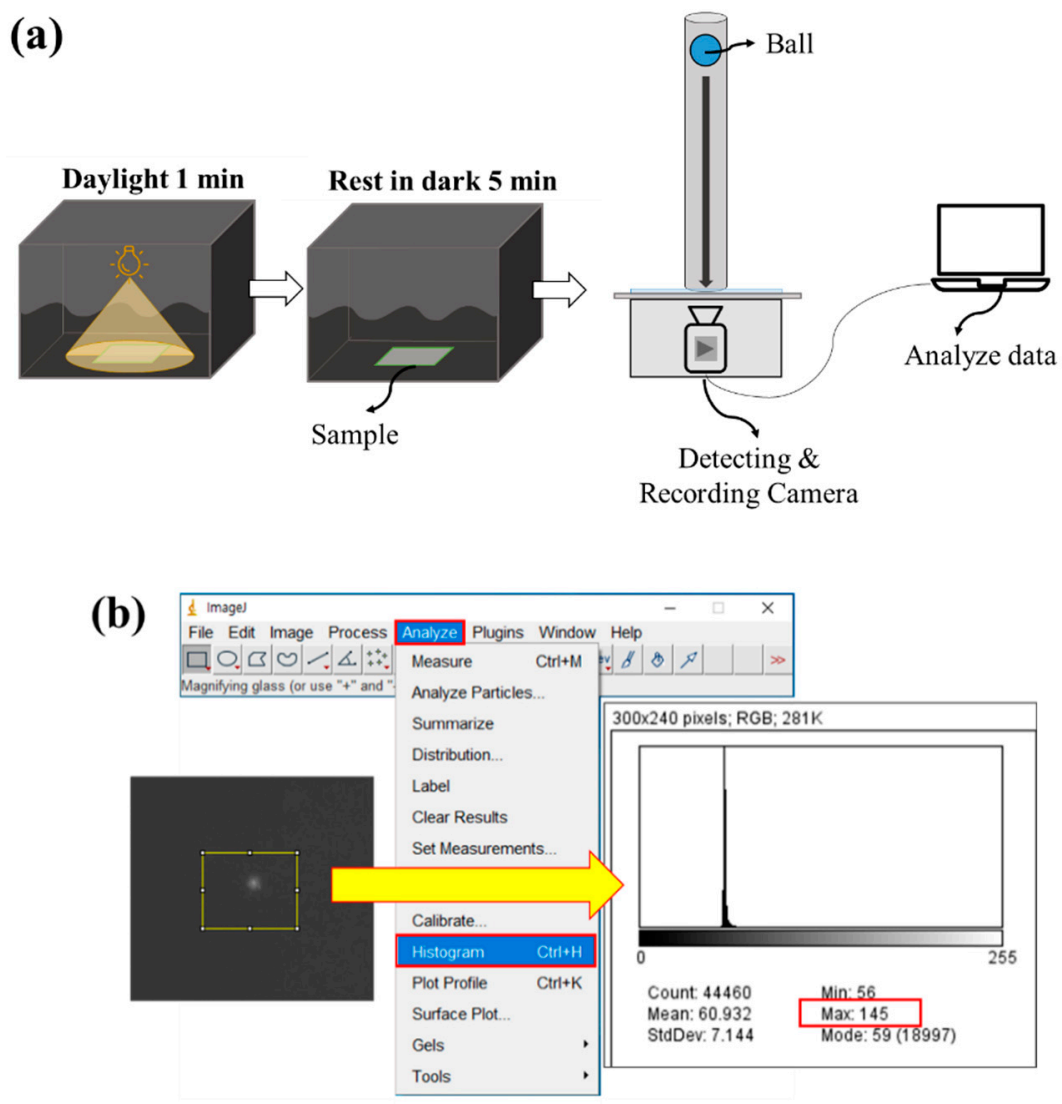

Figure 1. Light emission investigation of the mechanoluminescence (ML)/poly(vinylidene fluoride) (PVDF) composite. (a) Test setup for measurement of mechanoluminescence of ML composite fabrics; (b) image processing after drop ball test using ImageJ.

A Grasshopper 3 4.1MP ${ }^{\circledR}$ (FLIR Systems, Inc., Wilsonville, OR, USA) camera was used in conjunction with the PTGrey Fly Capture $2{ }^{\circledR}$ (FLIR Systems, Inc.) software for video recording the moment of the impact. Shutter speed, aperture, and focus were adjusted to collect the best possible image definition; these settings remained unaltered for all tests. The images were evaluated using the image processing software FIJI Image $22^{\circledR}[44,45]$, applying a greyscale range for measuring the PIV. The same detection procedure was applied in previous studies [46-49]. In this method, the PIV was calculated on the grayscale and the sum of the gray value in the selected area was divided by the number of pixels. As the light gets brighter, the PIV presents a higher value. The maximum PIV of the responding area is obtained for the analysis (Figure $1 \mathrm{~b}$ ) because the light intensity of the ML/polymer composite is focused on a micro point of view. The ball drop test setup and the image process are shown in Figure 1.

\subsection{Microscopic Analysis}

The fluorescence image of the composite fabrics was observed by the fluorescence microscope (U-HGLGPS, Olympus, Tokyo, Japan). The surface morphology and ML size were observed using a field-emission scanning electron microscope (FE-SEM, MERLIN Compact, Carl Zeiss, Jena, Germany), with a prior Pt coating $(\sim 10 \mathrm{~nm})$ at $10 \mathrm{~mA}$ for $180 \mathrm{~s}$ using a sputter coater (EM ACE200, Leica, Wetzlar, Germany). Energy-dispersive spectroscopy (EDS) analysis and elemental mapping were achieved by a NORAN system 7 attached to the SEM equipment. 


\subsection{Measurement of Water Vapor Transmission Rate (WVTR)}

The water vapor transmission rate (WVTR) of the composite fabric was measured following KS K 0594:2015 testing methods for the water vapor transmission rate of textile fabrics [50]. A combined temperature and humidity chamber (PL-3KPH, Espec Corp., Osaka, Japan) was used. The thickness of the ML/PVDF specimen used for the experiment was $0.1 \pm 0.02 \mathrm{~mm}$ and ML/PAN was $0.13 \pm 0.02 \mathrm{~mm}$. A composite sample with a $7 \mathrm{~cm}$ diameter was fixed on a water-permeable cup containing $33 \mathrm{~g}$ of calcium chloride $\left(\mathrm{CaCl}_{2}\right)$ at $40 \pm 2{ }^{\circ} \mathrm{C}, 90 \pm 5 \% \mathrm{RH}$ condition. The cup with a composite sample must maintain a $3 \mathrm{~mm}$ distance between the sample and the $\mathrm{CaCl}_{2}$. After $1 \mathrm{~h}$, the weight $\left(a_{1}\right)$ of the specimen is measured immediately. Then, put the test specimen back into the chamber and take out the specimen again to measure the weight $\left(a_{2}\right)$ after the following $1 \mathrm{~h}$. The mass change $(\mathrm{g})$ was measured after a predetermined time to calculate the WVTR by the following equation.

$$
P=\frac{a_{2}-a_{1}}{S}
$$

$P:$ water vapor transmission rate $\left(\mathrm{g} / \mathrm{m}^{2} \cdot \mathrm{h}\right)$;

$a_{1}-a_{2}$ : mass change of water-permeable cup with $\mathrm{CaCl}_{2}$ after $1 \mathrm{~h}(\mathrm{~g} / \mathrm{h})$;

$S:$ area $\left(\mathrm{m}^{2}\right)$ of the sample exposed to the moisture absorbent.

\subsection{Finite Element Analysis for Normal Stress}

Abaqus/Explicit [51] was utilized for a drop ball test simulation. The ML composite material is assumed to be linearly elastic and its properties used in the simulation are listed in Table 1.

Table 1. Materials properties.

\begin{tabular}{cccc}
\hline Part & Density $\left.\mathbf{( k g} / \mathbf{m}^{\mathbf{3}}\right)$ & Elastic Modulus $(\mathbf{G P a})$ & Poisson's Ratio \\
\hline Composites & 1780 & 2.27 & 0.225 \\
\hline Support & 2700 & 70.0 & 0.330 \\
\hline
\end{tabular}

The finite element analysis (FEA) model for the drop simulation contained three parts in total, as shown in Figure 2. Assuming the ML composites to be homogeneous, a quarter model was investigated in this simulation due to the symmetry. The composite samples were modeled by a 4-noded shell element type on the middle surface. The 8-noded 3D solid element type was chosen to model the supporter, and the ball was modeled by a 4-noded discrete rigid element type. As boundary conditions, the bottom of the support was fixed and symmetry displacement conditions on the side surface $(U x=0$ or $U z=0)$ were prescribed. Contact surfaces between possible contacting parts were defined, and the kinematic algorithm was applied as it is known as more accurate than the penalty method [52]. The kind of normal contact behavior was modeled by the "hard" contact option. Impact velocity was assigned as $2 \mathrm{~m} / \mathrm{s}$ derived by the law of energy conservation. The impact simulation time was $0.2 \mathrm{~ms}$.

To demonstrate the effect of thickness and layering, the maximum von Mises stress value on the impact area was compared. In the case of multiple layers, von Mises stress was obtained in the lowest layer because the stress value is highest in the lower layer. 
(a)

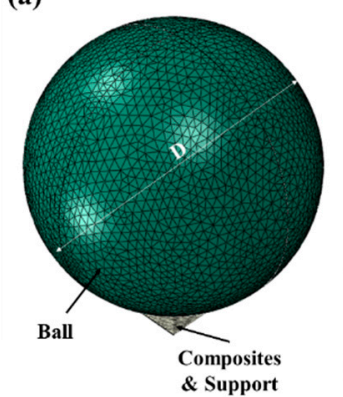

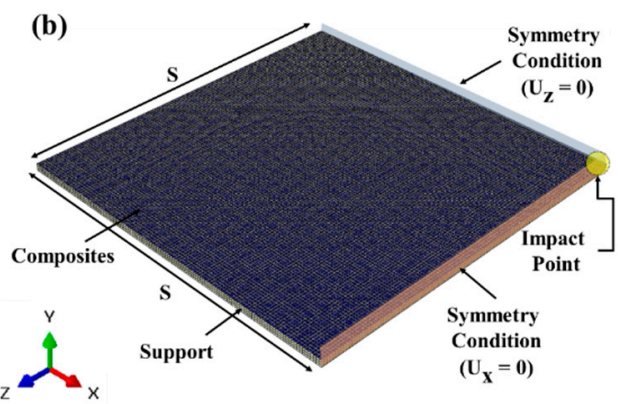

Figure 2. The geometry of the full model for drop test simulation. (a) Geometry of the full model, the diameter of the ball $(\mathrm{D})=25 \mathrm{~mm}$; (b) composite and support geometry of the quarter model, the length of square composites $(\mathrm{S})=10 \mathrm{~mm}$.

\section{Results and Discussion}

\subsection{Microscopic Observation of ML-Incorporated Composite Fabrics}

Fluorescence and SEM images of ML and ML composites were observed in Figure 3. Figure 3a,b show the morphology and size of ML particles. The average size of ML particles was measured to be $2.39 \mu \mathrm{m}$, with a wide range of particle size distribution. About $44 \%$ of ML particles were in the range of $1-2 \mu \mathrm{m}$. Figure $3 c$,d show the fluorescence images of electrospun ML/PVDF and ML/PAN, respectively. ML particles were randomly dispersed through the micro- and nanofibers without large aggregations. From Figure 3e-h, PVDF produced micro-sized fibers $(\sim 3.29 \mu \mathrm{m})$ with a mix of nano-sized fibers $(0.20 \mu \mathrm{m})$, and the small ML particles were embedded in relatively large fibers, while large ML particles were randomly dispersed throughout the electrospun web. The average diameter of ML/PVDF was $1.40 \mu \mathrm{m}$. PAN fibers were smaller than PVDF fibers, of which ranged $0.449 \sim 0.899 \mu \mathrm{m}$. Compared to PVDF, PAN fibers had a much narrower size distribution, with an average diameter of $0.63 \mu \mathrm{m}$. As ML particles were mostly larger than PAN fibers, many large ML particles were attached to the nanofibers rather than embedded in the fibers, while the submicron particles were still observed inside the fibers.

(a)

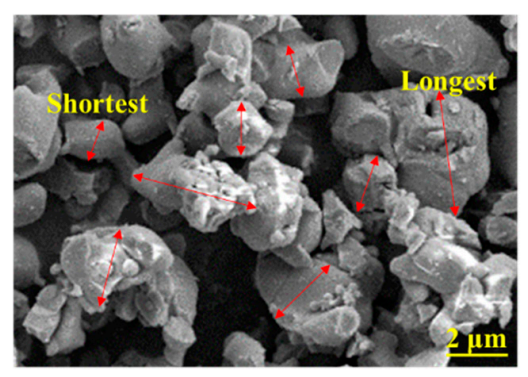

(c)

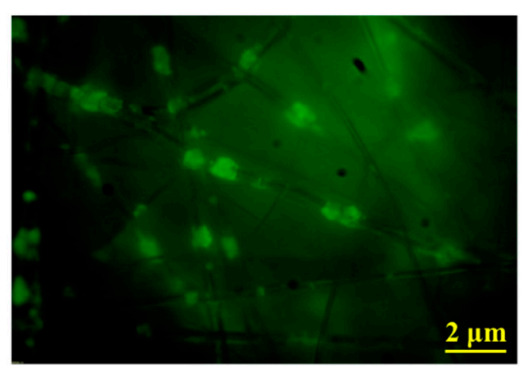

(b)

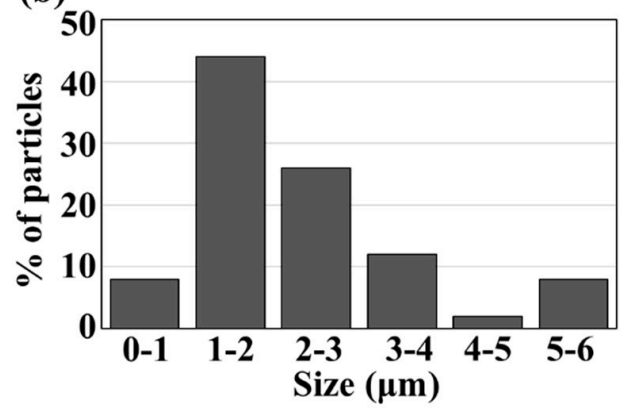

(d)

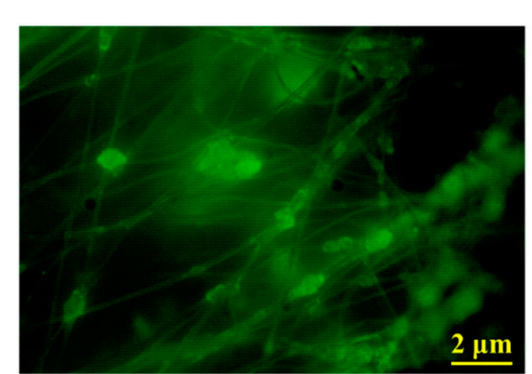

Figure 3. Cont. 
(e)

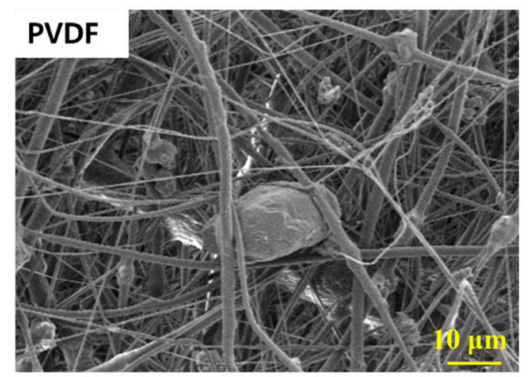

(g)

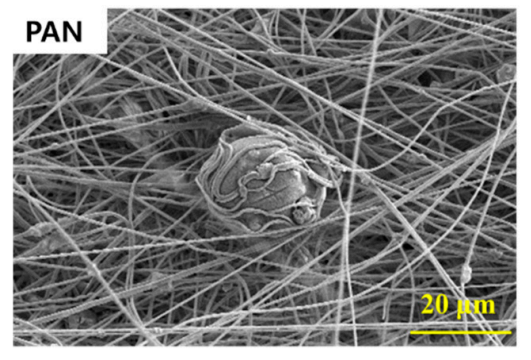

(f)

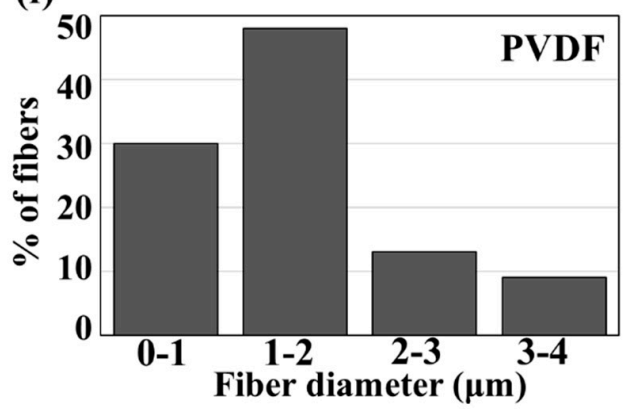

(h)

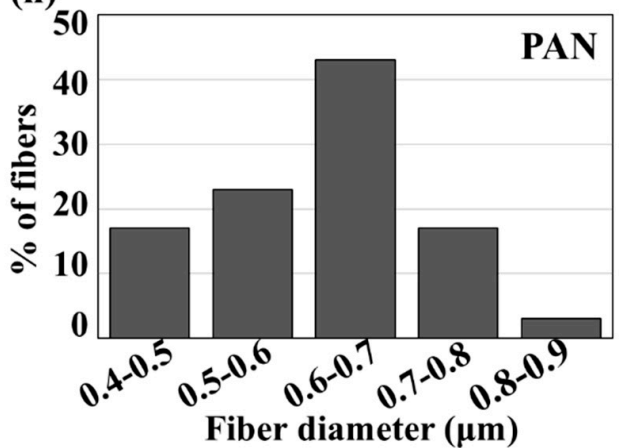

Figure 3. ML and ML-incorporated electrospun composites. (a) SEM of ML particles; (b) size distribution of ML particles; (c) fluorescence image of ML/PVDF fibers; (d) fluorescence image of ML/ polyacrylonitrile (PAN) fibers; (e) SEM image of ML/PVDF fibers; (f) diameter distribution of ML/PVDF fibers; (g) SEM image of ML/PAN fibers; (h) diameter distribution of ML/PAN fibers. Note. A total number of fifty ML particles were measured for size distribution; a total number of thirty fibers were measured for the diameter distribution of ML composites.

To examine the particle distribution in the fibrous composite, the energy-dispersive X-ray spectroscopy (EDS) mapping was observed in Figure 4. To verify the presence of materials in EDS, the atoms F, N, and Sr were selected to map the PVDF fibers, PAN fibers, and ML particles, respectively. Figure 4 corroborates that the ML particles were randomly and rather uniformly distributed throughout the fibrous composites.

(a)

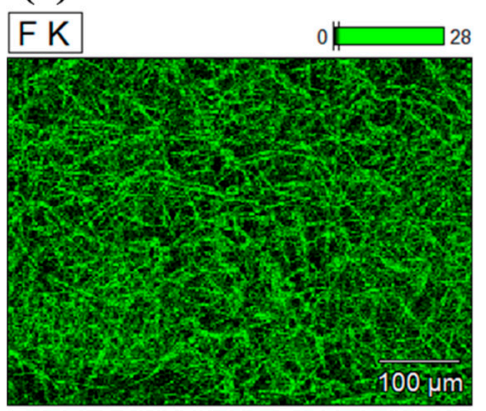

(b)

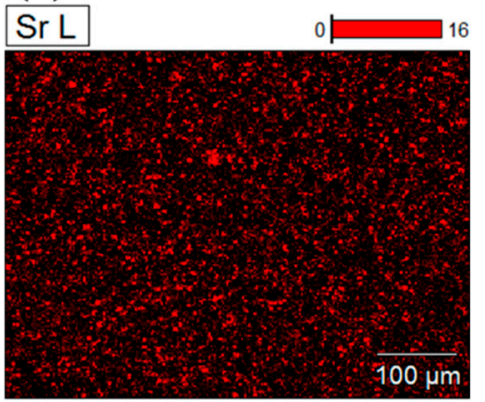

(c)

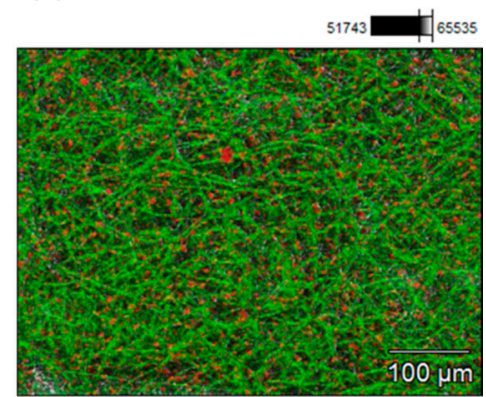

Figure 4. Cont. 
(d)

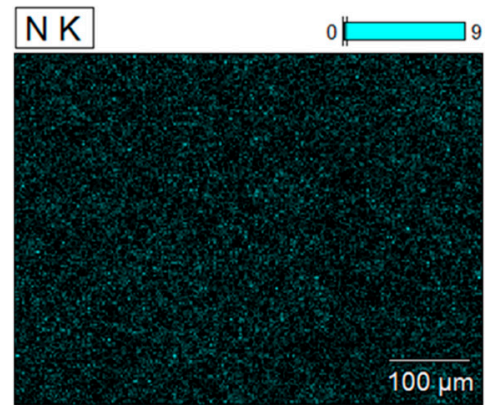

(e)

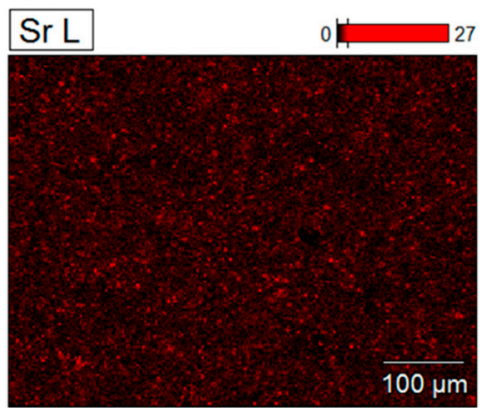

(f)

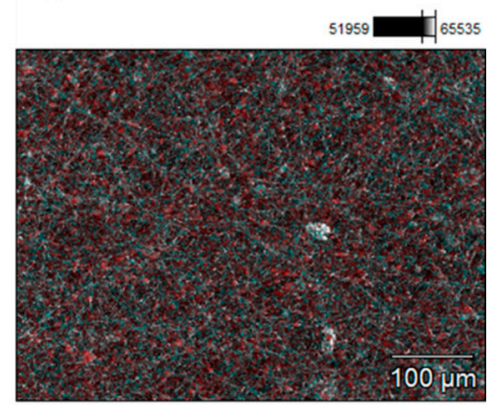

Figure 4. EDS mapping for PVDF/ML and PAN/ML. (a) Mapping for fluorine (F) in PVDF fibers; (b) mapping for strontium (Sr) in ML particles; (c) integrated image of F and Sr of ML/PVDF; (d) mapping for nitrogen (N) in PAN fibers; (e) mapping for strontium (Sr) in ML particles; (f) integrated image of $\mathrm{N}$ and $\mathrm{Sr}$ of ML/PAN.

\subsection{Light Emission of ML-Incorporated Electrospun Composites}

The PIV of ML/PVDF composite fabrics was measured from the ball drop test. To investigate the effects of composite thickness and layering on the ML intensity, composites with varying thickness $(0.1 \pm 0.02,0.2 \pm 0.02$, and $0.4 \pm 0.03 \mathrm{~mm})$ and varying numbers of layers (two layers of $0.1 \mathrm{~mm}$ fabric, four layers of $0.1 \mathrm{~mm}$ fabric, and two layers of $0.2 \mathrm{~mm}$ fabric) were measured for ML intensity (Figure 5).

(a)

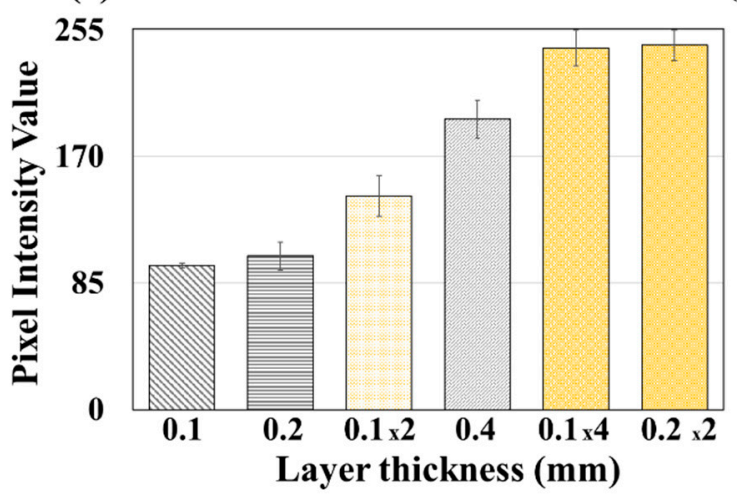

(b)
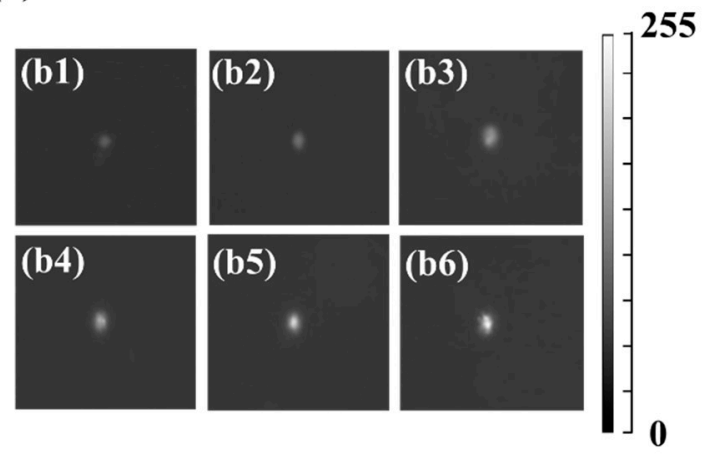

Figure 5. Pixel intensity value (PIV) of ML/PVDF composites with different thickness and layers. (a) The maximum PIV of ML/PVDF composites; (b1-b6) instant capture of ML/PVDF composites of a single layer of $0.1 \mathrm{~mm}$ fabric (b1), $0.2 \mathrm{~mm}$ (b2), 2 layers of $0.1 \mathrm{~mm}$ thickness (b3), a single layer of $0.4 \mathrm{~mm}(\mathbf{b} 4), 4$ layers of $0.1 \mathrm{~mm}$ fabric (b5), and 2 layers of $0.2 \mathrm{~mm}$ fabric (b6).

PIVs of 0.1 and $0.2 \mathrm{~mm}$ were about the same; however, the PIV of $0.4 \mathrm{~mm}$ was about twice that of $0.2 \mathrm{~mm}$. The effect of layering on the ML intensity was notable between the single layer of $0.2 \mathrm{~mm}$ fabric and the two layers of $0.1 \mathrm{~mm}$ fabric, as the two-layer construction with the same overall thickness displayed the higher PIV. For the fabric constructions with an overall thickness of $0.4 \mathrm{~mm}$, two-layer and four-layer constructions showed a higher PIV than a single layer of $0.4 \mathrm{~mm}$ fabric. The effect of layering on ML intensity was further examined by modeling.

\subsection{Simulation on Layering Effect}

To interpret the layering effect on the ML intensity, a drop simulation was executed by Abaqus/Explicit: in this analysis, the maximum stress values on the drop area of the composite fabric were compared for different thicknesses and layers. Figure 6 presents the von Mises stress contour and the stress-time curve. From Figure 6a, the von Mises stress value is concentrated at the impact point. The von Mises stress values of the multi-layer composite were higher than that 
of the single-layer composite. The stress development over time for the multi-layer construction and the single-layer construction was different, as the textiles in the multi-layer composites were not restrained; thus, the layers were in contact rather than fixed. Due to the existence of gaps between layers, the serial transmission of the impact energy from the top layer to the support occurs with short time intervals with mechanical interactions (i.e., secondary impact, slip, and friction) between layers. This could be a main cause for the higher PIV and stress as evidenced in the experimental tests and simulations, respectively. As multi-layer composites happen to separate, the stress wave propagation can change [53].

(a)

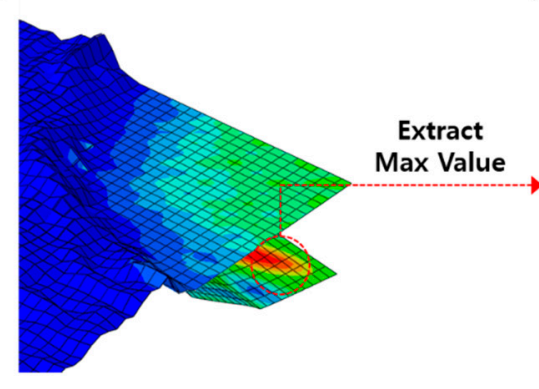

(b)

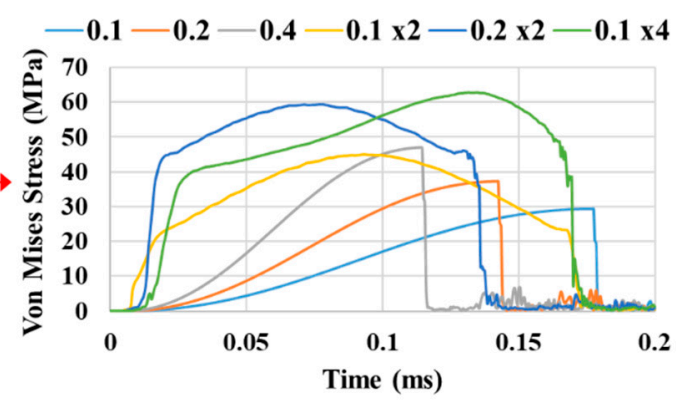

(c)

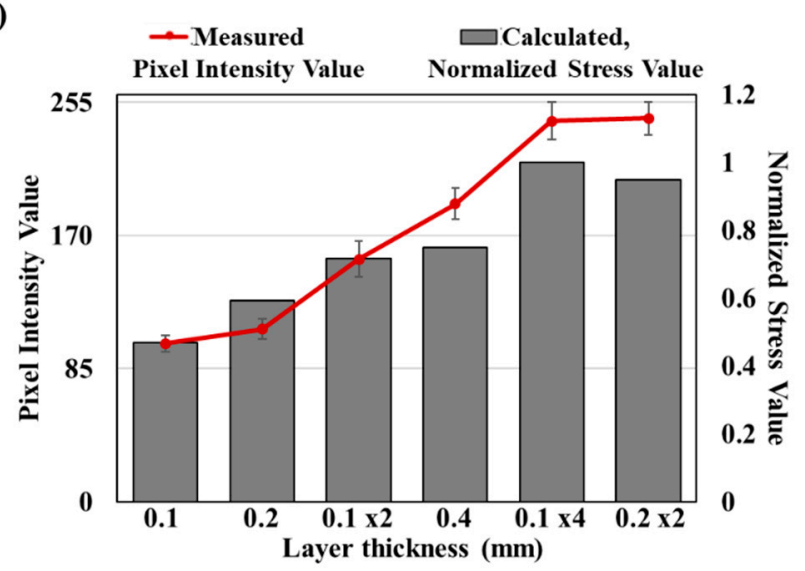

Figure 6. Von Mises stress value of ML/PVDF composites with different thicknesses and layers. (a) The von Mises stress contour. For the two-layer composites, the deformation scale factor of 10 was used; (b) von Mises stress curve as a function of time. (c) Comparison of simulated normalized stress value of ML/PVDF composites and actual PIV after experiments with different thicknesses and layers.

Figure $6 \mathrm{~b}$ represents the simulated values for the change of the stress on the composite overtime after the collision of the ball and the composite. The total simulation time was $0.2 \mathrm{~ms}$. The graph depicts that von Mises stress gets higher with multiple layers and the thickness. Figure $6 c$ shows the calculated value for the normalized maximum von Mises stress values (gray bar) and the measured PIV of the ML/PVDF composites (red line) with different thicknesses and layers. The normalized stress value is the stress value of the composite divided into the biggest stress value (calculated) in every condition. In that way, the biggest stress value becomes 1 in every experiment condition. To see the valid result, we collected only the largest stress value during $0.2 \mathrm{~ms}$ for each condition and normalized it. As shown on the graph, the normalized stress value from the simulation results displayed a similar tendency with the actual light intensity (measured) from the experiment. The multi-layer composites showed higher von Mises stress than single-layer composites with the same thickness. Certainly, the simulation results were not exactly equal to the experimental results; however, the simulation result was an approximate match with the experimental results for the effects of thickness and layering on the stress. 


\subsection{Effect of Composite Wettability on ML Intensity}

When ML materials containing alkaline earth aluminates interact with water, the properties of mechanoluminescence can be deteriorated due to the hydrolysis of ML. When ML is applied as a clothing textile, potential hydrolysis of ML in wet conditions puts a significant constraint on applications. The hydrolysis mechanism of SAOED is known as follows:

$$
\begin{aligned}
& 7 \mathrm{SrAl}_{2} \mathrm{O}_{4}+8 \mathrm{H}_{2} \mathrm{O} \rightarrow \mathrm{Sr}_{3} \mathrm{Al}_{2}(\mathrm{OH})_{12}+4 \mathrm{SrAl}_{3} \mathrm{O}_{5}(\mathrm{OH}) \\
& \mathrm{SrAl}_{2} \mathrm{O}_{4}+4 \mathrm{H}_{2} \mathrm{O} \rightarrow \mathrm{Sr}_{2}^{+}+2 \mathrm{OH}^{-}+\mathrm{Al}(\mathrm{OH})_{3} \\
& \mathrm{Sr}^{2+}+2 \mathrm{OH}^{-}+\mathrm{CO}_{2} \rightarrow \mathrm{SrCO}_{3}+\mathrm{H}_{2} \mathrm{O}
\end{aligned}
$$

When SAOED is exposed to a high-humidity condition, it can be readily decomposed into a mixture of $\mathrm{Sr}_{3} \mathrm{Al}_{2}(\mathrm{OH})_{12}$ and $4 \mathrm{SrAl}_{3} \mathrm{O}_{5}(\mathrm{OH})$ and those are further decomposed into strontium ion $\left(\mathrm{Sr}^{2+}\right)$ and hydroxide ions $\left(2 \mathrm{OH}^{-}\right)$. Then, the $\mathrm{Sr}^{2+}$ reacts with $\mathrm{CO}_{2}$ in the air to create the final product, $\mathrm{SrCO}_{3}$, which is a carbonate salt of strontium. The mechanism is the direct indication of the instability of SAOED at a humidity condition [54].

From the assumption that the wetting of SAOED leads to hydrolysis and deterioration of ML performance, the wettability of composite fabrics was examined. The wettability was represented by the water contact angles (CA) for the untreated ML composites, $\mathrm{O}_{2}$ plasma-treated ML composites, and $\mathrm{C}_{4} \mathrm{~F}_{8}$ PECVD-treated ML composites, respectively (Figure 7). The ML/PVDF was more hydrophobic $\left(\mathrm{CA} \sim 139.8^{\circ} \pm 2.6^{\circ}\right)$ than $\mathrm{ML} / \mathrm{PAN}\left(\mathrm{CA} \sim 63.5^{\circ} \pm 1.7^{\circ}\right)$. When both composites were treated with oxygen plasma, the surface turned into very hydrophilic with a CA of $0^{\circ}$. The fluorination of ML composites by the $\mathrm{C}_{4} \mathrm{~F}_{8}$ PECVD process made the fabrics more hydrophobic; the CAs of fluorinated ML/PVDF and fluorinated ML/PAN were $150.6 \pm 2.8^{\circ}$ and $143.2 \pm 1.4^{\circ}$, respectively. The wettability of ML composites with different surface treatments, measured by water contact angle, is shown in Figure 7.

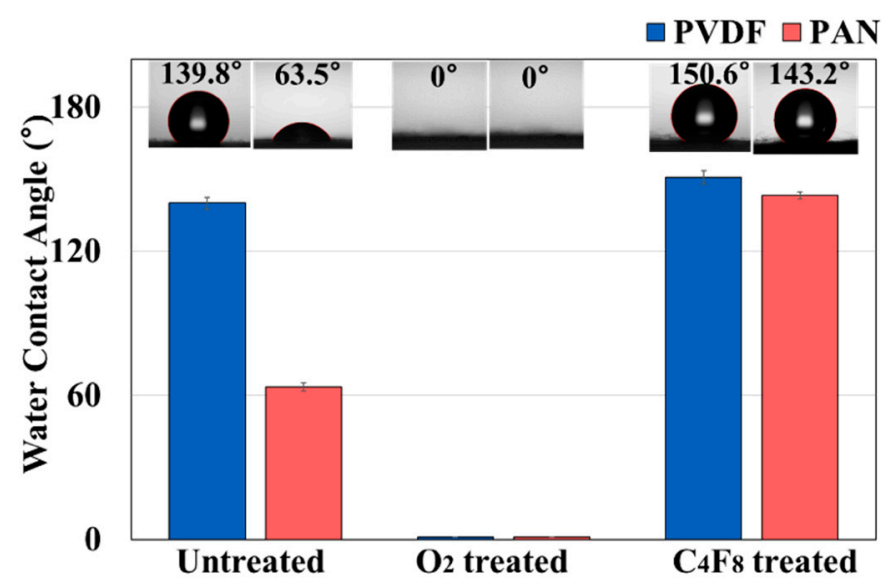

Figure 7. The water contact angle of the ML/PVDF and ML/PAN composites for different surface treatments including hydrophilic $\mathrm{O}_{2}$ plasma and hydrophobic $\mathrm{C}_{4} \mathrm{~F}_{8}$ plasma processes.

The ML intensity of composites with the varied wetting properties was investigated, before and after exposure to water. The tested ML/PVDF composite samples were two-layered with $0.1 \pm 0.01 \mathrm{~mm}$ thickness. The tested ML/PAN composite had a thickness of $\sim 0.15 \pm 0.02 \mathrm{~mm}$, and a single layer of ML/PAN composite was used. The composite fabrics, either PVDF or PAN, displayed the consistent level of PIVs in the dry state regardless of wetting properties that were varied by the plasma treatments. To examine the effect of water exposure on the ML intensity, the composite fabrics were immersed in water for $30 \mathrm{~min}$, subsequently removing the dripping water by placing on absorbent paper for about $1 \mathrm{~min}$, then the wet composite fabrics were subjected to the ball drop test. Thirty repetitions of the ball drop test were conducted for every six samples. The percentage of water add-on was calculated by the following formula: 
$\frac{\text { The weight of wet composite }(\mathrm{g})-\text { The weight of dry composite }(\mathrm{g})}{\text { The weight of dry composite }(\mathrm{g})} \times 100(\%)$

As shown in Table 2, hydrophilized $\mathrm{O}_{2}$-treated composites showed a large amount of water add-on, while the hydrophobized $\mathrm{C}_{4} \mathrm{~F}_{8}$-treated composites showed a smaller amount of water add-on. PVDF is intrinsically hydrophobic, and the water add-on of ML/PVDF was much less than that of ML/PAN. The PIVs of the ML/PVDF and ML/PAN composite fabrics in dry and wet states are shown in Table 2 and Figure 8. For all samples, the maximum PIV appeared at $\sim 4 \mathrm{msec}$, then the light intensity gradually decreased (Figure $8 \mathrm{a}, \mathrm{b}$ ). While the PIVs in the dry state were relatively consistent, the PIVs decreased as the water add-on by the composite fabrics increased. The hydrophilic ML/PAN decreased PIV from 141 in a dry state to 100 in a wet state.

Table 2. Wettability, water add-on, and ML intensity of ML/polymer composite fabrics.

\begin{tabular}{cccc|ccc}
\hline \multirow{2}{*}{ Measurement } & \multicolumn{3}{c|}{ ML/PVDF } & \multicolumn{3}{c}{ ML/PAN } \\
\cline { 2 - 7 } & Untreated & $\mathbf{O}_{\mathbf{2}}$ Treated & Fluorinated & Untreated & $\mathbf{O}_{\mathbf{2}}$ Treated & Fluorinated \\
\hline Contact angle $\left(^{\circ}\right.$ ) & 140 & 0 & 151 & 63.5 & 0 & 143 \\
Water add-on $(\%)$ & 6.27 & 239 & 2.38 & 569 & 708 & 11.2 \\
PIV in dry state & 162 & 163 & 167 & 141 & 150 & 145 \\
PIV in wet state & 150 & 97 & 150 & 100 & 110 & 157 \\
\hline
\end{tabular}

As PVDF is intrinsically hydrophobic, the ML/PVDF composite did not absorb water much, and the PIV was not changed significantly. The water add-on of ML/PVDF was mostly the surface-adsorbed water, not the one absorbed into the composite fibers. When the PVDF composite was hydrophilized by the $\mathrm{O}_{2}$ treatment, the water add-on increased, resulting in a considerable decrease in PIV. When the PVDF composite was further hydrophobized by fluorination $\left(\mathrm{C}_{4} \mathrm{~F}_{8}\right.$ PECVD), the PIV was not much changed after water immersion as the water add-on was insignificant.

The ML/PAN composite fabric appeared moderately hydrophilic, and the mass of wet composites was $\sim 569 \%$ of the dry composite; accordingly, the PIV decreased significantly when wet. The further hydrophilized ML/PAN fabric by $\mathrm{O}_{2}$ plasma showed a similar level of PIV when wet. The result corresponds to the previous studies that reported a decreased ML performance with a water add-on [55]. The fluorinated ML/PAN composite by the $\mathrm{C}_{4} \mathrm{~F}_{8}$ treatment made the composite hydrophobic, decreasing the water add-on (11.2\%) when immersed in water. The PIV of fluorinated ML/PAN in the wet state did not decrease, resulting in moisture-insensitive luminescence performance. As PAN is hydrophilic, when ML is applied to acrylic textiles (PAN), the ML performance may deteriorate when the textile gets wet by rain or sweat. In this case, hydrophobic treatment may be beneficial for improving the ML performance when the textiles are wet. This study provided a practical and facile way of overcoming the moisture-dependent ML performance of ML-incorporated composites.

(a)

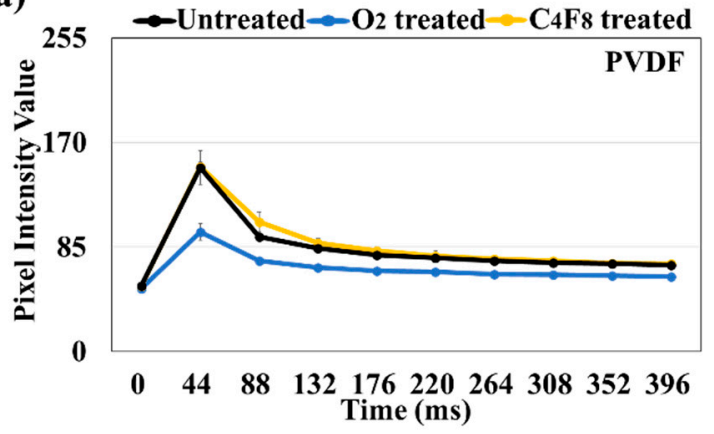

(b)

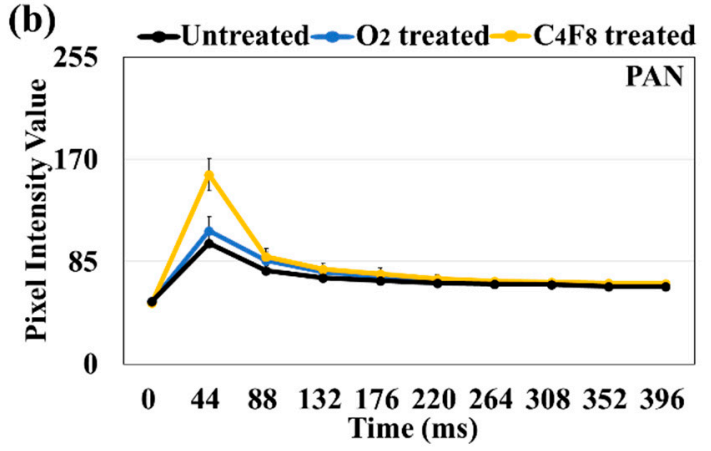

Figure 8. Cont. 
(c)

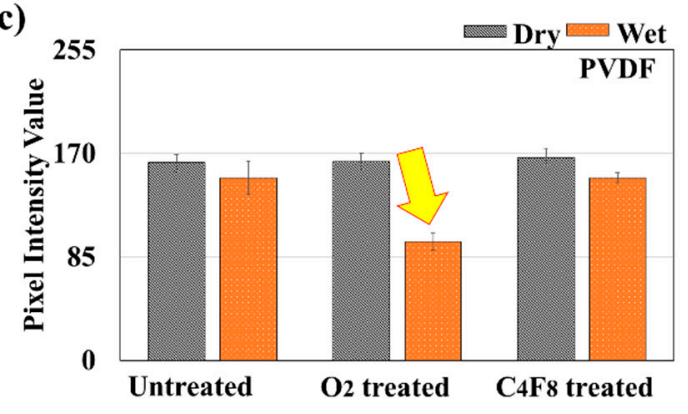

(e)

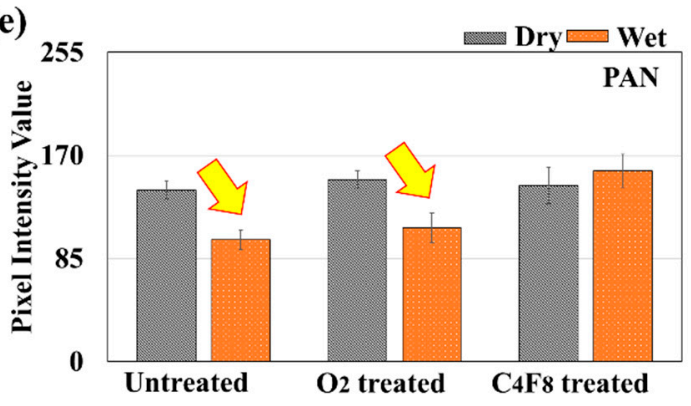

(d)

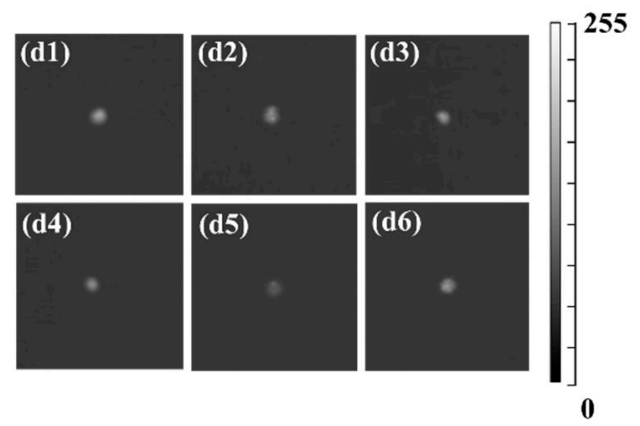

(f)
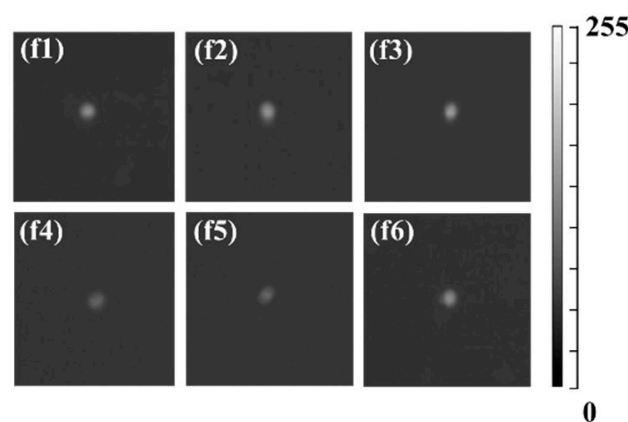

Figure 8. Mechanoluminescence intensity for ML composites with different treatments. (a) PIV of ML/PVDF with time in the wet state; (b) PIV of ML/PAN with time in the wet state; (c) maximum PIV of ML/PVDF in dry and wet states; (d1-d3) PIV image of ML/PVDF untreated, $\mathrm{O}_{2}$-treated, and $\mathrm{C}_{4} \mathrm{~F}_{8}$-treated, respectively, in a dry state; (d4-d6) PIV image of ML/PVDF untreated, $\mathrm{O}_{2}$-treated, and $\mathrm{C}_{4} \mathrm{~F}_{8}$-treated, respectively, in the wet state; (e) maximum PIV of ML/PAN in dry and wet states; (f1-f3) PIV image of ML/PAN untreated, $\mathrm{O}_{2}$-treated, and $\mathrm{C}_{4} \mathrm{~F}_{8}$-treated, respectively, in a dry state; (f4-f6) PIV image of ML/PAN untreated, $\mathrm{O}_{2}$-treated, and $\mathrm{C}_{4} \mathrm{~F}_{8}$-treated, respectively, in the wet state.

\subsection{Water Vapor Transmission Rate (WVTR) of Composite Fabrics}

As a representative measurement of breathability, the water vapor transmission rate (WVTR) of the composite fabric was measured (Figure 9). WVTR is generally affected by surface wettability and porosity of the material, as those factors influence the adsorption and transport of water vapor [56,57]. The hydrophobic ML/PVDF composite showed a higher WVTR than the hydrophilic ML/PAN. In the ML/PAN composite, hydrophobized $\left(\mathrm{C}_{4} \mathrm{~F}_{8}\right)$ samples showed similar or slightly higher WVTR than the untreated or $\mathrm{O}_{2}$-treated composite. This result depicts that the hydrophobic coating with $\mathrm{C}_{4} \mathrm{~F}_{8}$ PECVD did not adversely influence the water vapor permeability; on the contrary, the hydrophobic coating treatment slightly improved the vapor permeability. This is because the hydrophobic surface absorbs or traps the water molecule and releases a vaporous water molecule rather quickly. When the fiber surface becomes very hydrophilic, its sorption capacity increases and the surface tends to hold water molecules more strongly, delaying the transmission time [57,58]. 


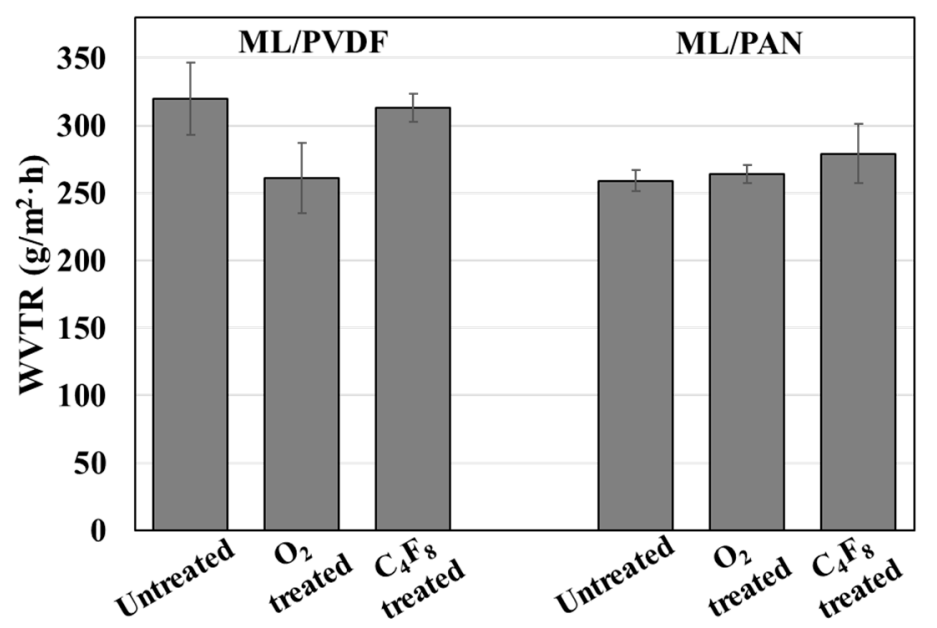

Figure 9. Effect of hydrophobic and hydrophilic treatment for ML/PVDF and ML/PAN composite fabrics on water vapor transmission rate (WVTR).

\section{Conclusions}

Mechanoluminescent (ML) composite fabrics, which emit light when exposed to sudden mechanical stress, were fabricated by electrospinning of ML-incorporated PVDF and PAN fibers. Notably, multi-layer constructions displayed distinctly higher ML intensities than the single-layer construction of the same overall thickness. The ML performance was deteriorated when the ML-incorporated composite fabric absorbed a significant amount of water. Comparing ML/PVDF and ML/PAN, the hydrophilic ML/PAN composite showed a reduced ML intensity in wet conditions, while the ML performance of hydrophobic ML/PVDF was almost intact after water exposure. When the wetting properties of ML/PVDF were modified to be hydrophilic by the $\mathrm{O}_{2}$ plasma process, the ML intensity decreased for the originally hydrophobic ML/PVDF. The reduced ML performance in wet conditions is a potential problem for application in clothing, as the composite fabric may experience wetting by rain or sweat. When the composite fabric was modified for being hydrophobic by the $\mathrm{C}_{4} \mathrm{~F}_{8}$ PECVD process, the ML/PAN did not absorb water much, and the ML performance was not deteriorated after being immersed in water. To conclude, the study intended to suggest a facile strategy to fabricate the breathable composite fabrics of which the performance is moisture-insensitive. The approach of this study is novel in that the simple technique of the plasma-enhanced chemical vapor deposition (PECVD) process was applied to composite fabrics to optimize the ML performance in wet conditions, still maintaining the breathability of fabrics. It is expected that the resulting material can be applied as a battery-free mechanoluminescent sensor in smart textiles.

Author Contributions: Investigation and writing, H.L.; investigation and writing, E.C.; experimental setup, verification, and writing, T.W.K.; simulation and writing, S.L.K.; supervision, fund acquisition and writing. G.J.Y.; conceptualization, supervision, fund acquisition and writing, J.K. All authors have read and agreed to the published version of the manuscript.

Funding: This work was supported by the National Research Foundation of Korea (NRF) grant funded by the Korea government (MSIT) (NRF-2020R1F1A1074295) and Institute of Engineering Research at Seoul National University.

Conflicts of Interest: The authors declare no conflict of interest.

\section{References}

1. Stoppa, M.; Chiolerio, A. Wearable electronics and smart textiles: A critical review. Sensors 2014, 14, 11957-11992. [CrossRef] [PubMed]

2. Cherenack, K.; van Pieterson, L. Smart textiles: Challenges and opportunities. J. Appl. Phys. 2012, 112, 091301. [CrossRef]

3. Suga, T.; Konishi, H.; Nishide, H. Photocrosslinked nitroxide polymer cathode-active materials for application in an organic-based paper battery. Chem. Commun. 2007, 17, 1730-1732. [CrossRef] [PubMed] 
4. Pushparaj, V.L.; Shaijumon, M.M.; Kumar, A.; Murugesan, S.; Ci, L.; Vajtai, R.; Linhardt, R.J.; Nalamasu, O.; Ajayan, P.M. Flexible energy storage devices based on nanocomposite paper. PNAS. 2007, 104, 13574-13577. [CrossRef] [PubMed]

5. Kaltenbrunner, M.; Kettlgruber, G.; Siket, C.; Schwödiauer, R.; Bauer, S. Stretchable batteries: Arrays of ultracompliant electrochemical dry gel cells for stretchable electronics. Adv. Mater. 2010, 22, 2065-2067. [CrossRef]

6. Futaba, D.N.; Hata, K.; Yamada, T.; Hiraoka, T.; Hayamizu, Y.; Kakudate, Y.; Tanaike, O.; Hatori, H.; Yumura, M.; Iijima, S. Shape-engineerable and highly densely packed single-walled carbon nanotubes and their application as super-capacitor electrodes. Nat. Mater. 2006, 5, 987-994. [CrossRef]

7. Bedeloglu, A.; Demir, A.; Bozkurt, Y.; Sariciftci, N.S. A photovoltaic fiber design for smart textiles. Text. Res. J. 2010, 80, 1065-1074. [CrossRef]

8. Pope, J.; Lekakou, C. Thermoelectric polymer composite yarns and an energy harvesting wearable textile. Smart. Mater. Struct. 2019, 28, 095006. [CrossRef]

9. Hanson, M.A.; Powell Jr, H.C.; Barth, A.T.; Ringgenberg, K.; Calhoun, B.H.; Aylor, J.H.; Lach, J. Body area sensor networks: Challenges and opportunities. J. Comput. 2009, 42, 58-65. [CrossRef]

10. Thomas, J.P.; Qidwai, M.A.; Kellogg, J.C. Energy scavenging for small-scale unmanned systems. J. Power Sources 2006, 159, 1494-1509. [CrossRef]

11. Jeong, S.M.; Song, S.; Lee, S.K.; Ha, N.Y. Color manipulation of mechanoluminescence from stress-activated composite films. Adv. Mater. 2013, 25, 6194-6200. [CrossRef]

12. Wang, X.; Zhang, H.; Yu, R.; Dong, L.; Peng, D.; Zhang, A.; Zhang, Y.; Liu, H.; Pan, C.; Wang, Z.L. Dynamic pressure mapping of personalized handwriting by a flexible sensor matrix based on the mechanoluminescence process. Adv. Mater. 2015, 27, 2324-2331. [CrossRef] [PubMed]

13. Azad, A.I.; Rahimi, M.R.; Yun, G.J. Quantitative full-field strain measurements by SAOED $\left(\mathrm{SrAl}_{2} \mathrm{O}_{4}: \mathrm{Eu}^{2+}\right.$, $\mathrm{Dy}^{3+}$ ) mechanoluminescent materials. Smart. Mat. Struct. 2016, 25, 095032. [CrossRef]

14. Li, C.; Xu, C.; Imai, Y.; Bu, N. Real-time visualisation of the Portevin-Le Chatelier effect with mechanoluminescent-sensing film. Strain 2011, 47, 483-488. [CrossRef]

15. Gnidakouong, J.R.N.; Yun, G.J. Dislocation density level induced divergence between stress-free afterglow and mechanoluminescence in $\mathrm{SrAl}_{2} \mathrm{O}_{4}: \mathrm{Eu}^{2+}, \mathrm{Dy}^{3+}$. Ceram. Int. 2019, 45, 1794-1802. [CrossRef]

16. Webbe, T.; You, H.; Hemmatian, T.; Kim, J.; Yun, G. Enhancement of mechanoluminescence sensitivity of $\mathrm{SrAl}_{2} \mathrm{O}_{4}: \mathrm{Eu}^{2+}, \mathrm{Dy}^{3+} /$ Epoxy composites by ultrasonic curing treatment method. Compos. Interfaces. 2020, 2020, 1-23.

17. Peng, D.; Chen, B.; Wang, F. Recent advances in doped mechanoluminescent phosphors. ChemPlusChem 2015, 80, 1209. [CrossRef]

18. Yamamoto, H.; Matsuzawa, T. Mechanism of long phosphorescence of $\mathrm{SrAl}_{2} \mathrm{O}_{4}: \mathrm{Eu}^{2+}$, $\mathrm{Dy}^{3+}$ and $\mathrm{CaAl}_{2} \mathrm{O}_{4}: \mathrm{Eu}^{2+}, \mathrm{Nd}^{3+}$. J. Lumin. 1997, 72-74, 287-289. [CrossRef]

19. Clabau, F.; Rocquefelte, X.; Jobic, X.; Deniard, P.; Whangbo, M.-H.; Garcia, A.; Le Mercier, T. Mechanism of phosphorescence appropriate for the long-lasting phosphors $\mathrm{Eu}^{2+}$-doped $\mathrm{SrAl}_{2} \mathrm{O}_{4}$ with codopants $\mathrm{Dy}^{3+}$ and $\mathrm{B}^{3+}$. Chem. Mater. 2005, 17, 3904-3912. [CrossRef]

20. Someya, S.; Ishii, K.; Munakata, T.; Saeki, M. Lifetime-based measurement of stress during cyclic elastic deformation using mechanoluminescence of $\mathrm{SrAl}_{2} \mathrm{O}_{4}: \mathrm{Eu}^{2+}$. Opt. Express. 2014, 22, 21991-21998. [CrossRef]

21. Yun, G.J.; Rahimi, M.R.; Gandomi, A.H.; Lim, G.-C.; Choi, J.-S. Stress sensing performance using mechanoluminescence of $\mathrm{SrAl}_{2} \mathrm{O}_{4}: \mathrm{Eu}(\mathrm{SAOE})$ and $\mathrm{SrAl}_{2} \mathrm{O}_{4}: \mathrm{Eu}, \mathrm{Dy}(\mathrm{SAOED})$ under mechanical loadings. Smart. Mater. Struct. 2013, 22, 055006. [CrossRef]

22. Fu, X.; Yamada, H.; Xu, C.-N. Property of highly oriented $\mathrm{SrAl}_{2} \mathrm{O}_{4}$ : Eu: Eu film on quartz glass substrates and its potential application in stress sensor. J. Electrochem. Soc. 2009, 156, J249. [CrossRef]

23. Zhang, J.-C.; Fan, X.-H.; Yan, X.; Xia, F.; Kong, W.; Long, Y.-Z.; Wang, X. Sacrificing trap density to achieve short-delay and high-contrast mechanoluminescence for stress imaging. Acta Mater. 2018, 152, 148-154. [CrossRef]

24. Kim, J.S.; Kwon, Y.-N.; Sohn, K.-S. Dynamic visualization of crack propagation and bridging stress using the mechano-luminescence of SrAl2O4: Eu:(Eu, Dy, Nd). Acta Mater. 2003, 51, 6437-6442. [CrossRef]

25. Kim, J.S.; Sohn, K.S.; Kwon, Y.N.; Ban, G.S.; Lee, K.H. Detection of crack propagation in alumina using $\mathrm{SrAl}_{2} \mathrm{O}_{4}$ : Eu:(Eu, Dy) luminescent paint. Mater. Sci. Forum. 2007, 539-543, 2264-2268. [CrossRef] 
26. Jang, I.Y.; Kim, S.K.; Kim, J.S.; Ann, K.Y.; Cho, C.G. Detection of reinforced concrete crack using mechano-luminescence paint. Appl. Mech. Mater. 2013, 316-317, 1049-1054. [CrossRef]

27. Calderón-Olvera, R.; Albanés-Ojeda, E.; García-Hipólito, M.; Hernández-Alcántara, J.; Álvarez-Perez, M.; Falcony, C.; Alvarez-Fregoso, O. Characterization of luminescent $\mathrm{SrAl}_{2} \mathrm{O}_{4}$ films doped with terbium and europium ions deposited by ultrasonic spray pyrolysis technique. Ceram. Int. 2018, 44, 7917-7925.

28. Yamada, H.; Fu, X.Y.; Xu, C.N. Triboluminescence of SrAl2O4: Eu film with strong adhesion fabricated by a combination of RF magnetron sputtering and post-annealing treatment. Key Eng. Mater 2008, 368-372, 1362-1365. [CrossRef]

29. Fujio, Y.; Xu, C.-N.; Nishibori, M.; Teraoka, Y.; Kamitani, K.; Terasaki, N.; Ueno, N. Development of highly sensitive mechanoluminescent sensor aiming at small strain measurement. J. Adv. Dielectr. 2014, 4, 1450016. [CrossRef]

30. Fujio, Y.; Xu, C.-N.; Terasawa, Y.; Sakata, Y.; Yamabe, J.; Ueno, N.; Terasaki, N.; Yoshida, A.; Watanabe, S.; Murakami, Y. Sheet sensor using $\mathrm{SrAl}_{2} \mathrm{O}_{4}$ : Eu mechanoluminescent material for visualizing inner crack of high-pressure hydrogen vessel. Int. J. Hydrog. Energy. 2016, 41, 1333-1340. [CrossRef]

31. Sohn, K.-S.; Cho, M.Y.; Kim, M.; Kim, J.S. A smart load-sensing system using standardized mechano-luminescence measurement. Opt. Express. 2015, 23, 6073-6082. [CrossRef] [PubMed]

32. Zhang, J.-C.; Xu, C.-N.; Kamimura, S.; Terasawa, Y.; Yamada, H.; Wang, X. An intense elastico-mechanoluminescence material CaZnOS: $\mathrm{Mn}^{2+}$ for sensing and imaging multiple mechanical stresses. Opt. Express. 2013, 21, 12976-12986. [CrossRef] [PubMed]

33. Nance, J.; Sparks, T.D. Comparison of coatings for $\mathrm{SrAl}_{2} \mathrm{O}_{4}: \mathrm{Eu}^{2+}, \mathrm{Dy}^{3+}$ powder in waterborne road striping paint under wet conditions. Prog. Org. Coat. 2020, 144, 105637. [CrossRef]

34. Sikandar, M.A.; Ahmad, W.; Khan, M.H.; Ali, F.; Waseem, M. Effect of water resistant $\mathrm{SiO}_{2}$ coated $\mathrm{SrAl}_{2} \mathrm{O}_{4}$ : $\mathrm{Eu}^{2+}, \mathrm{Dy}^{3+}$ persistent luminescence phosphor on the properties of Portland cement pastes. Constr. Build. Mater. 2019, 228, 116823. [CrossRef]

35. Qu, Y.; Liu, Y.; Yu, C.; Zhu, G.; Sha, L.; Yang, Y.; Zheng, M.; Lei, B. Rapid combustion method for surface modification of strontium aluminate phosphors with high water resistance. Appl. Surf. Sci. 2012, 258, 6814-6818. [CrossRef]

36. Zhu, Y.; Zeng, J.; Li, W.; Xu, L.; Guan, Q.; Liu, Y. Encapsulation of strontium aluminate phosphors to enhance water resistance and luminescence. Appl. Surf. Sci. 2009, 255, 7580-7585. [CrossRef]

37. Chang, S.; Wang, M.; Zhang, F.; Liu, Y.; Liu, X.; Yu, D.G.; Shen, H. Sheath-separate-core nanocomposites fabricated using a trifluid electrospinning. Mater. Des. 2020, 192, 108782. [CrossRef]

38. Wang, M.; Hou, J.; Yu, D.G.; Li, S.; Zhu, J.; Chen, Z. Electrospun tri-layer nanodepots for sustained release of acyclovir. J. Alloys Compd. 2020, 2020, 156471. [CrossRef]

39. Park, S.; Yuan, Y.; Choi, K.; Choi, S.O.; Kim, J. Doxorubicin Release Controlled by Induced Phase Separation and Use of a Co-Solvent. Materials 2018, 11, 681. [CrossRef]

40. Song, K.; Lee, J.; Choi, S.-O.; Kim, J. Interaction of surface energy components between solid and liquid on wettability, and its application to textile anti-wetting finish. Polymers 2019, 11, 498. [CrossRef]

41. Yuan, Y.; Choi, K.; Choi, S.-O.; Kim, J. Early stage release control of an anticancer drug by drug-polymer miscibility in a hydrophobic fiber-based drug delivery system. RSC Adv. 2018, 8, 19791-19803. [CrossRef]

42. Roh, S.; Kim, S.; Kim, J. Facile functionalization via plasma-enhanced chemical vapor deposition for the effective filtration of oily aerosol. Polymers 2019, 11, 1490. [CrossRef] [PubMed]

43. Jung, S.; An, J.; Na, H.; Kim, J. Surface energy of filtration media influencing the filtration performance against solid particles, oily aerosol, and bacterial aerosol. Polymers 2019, 11, 935. [CrossRef] [PubMed]

44. Rueden, C.T.; Eliceiri, K.W. ImageJ for the next generation of scientific image data. Microsc. Microanal. 2019, 25, 142-143. [CrossRef]

45. Schneider, C.A.; Rasband, W.S.; Eliceiri, K.W. NIH Image to ImageJ: 25 years of image analysis. Nat. Methods. 2012, 9, 671-675. [CrossRef] [PubMed]

46. Bazhin, D.N.; Kudyakova, Y.S.; Bogomyakov, A.S.; Slepukhin, P.A.; Kim, G.A.; Burgart, Y.V.; Saloutin, V.I. Dinuclear lanthanide-lithium complexes based on fluorinated $\beta$-diketonate with acetal group: Magnetism and effect of crystal packing on mechanoluminescence. Inorg. Chem. Front. 2019, 6, 40-49. [CrossRef]

47. Kim, J.S.; Kibble, K.; Kwon, Y.N.; Sohn, K.S. Rate-equation model for the loading-rate-dependent mechanoluminescence of $\mathrm{SrAl}_{2} \mathrm{O}_{4}: \mathrm{Eu}^{2+}, \mathrm{Dy}^{3+}$. Opt. Lett. 2009, 34, 1915-1917. [CrossRef] 
48. Kim, J.S.; Kwon, Y.N.; Shin, N.; Sohn, K.S. Visualization of fractures in alumina ceramics by mechanoluminescence. Acta Mater. 2005, 53, 4337-4343. [CrossRef]

49. Li, C.; Xu, C.N.; Zhang, L.; Yamada, H.; Imai, Y. Dynamic visualization of stress distribution on metal by mechanoluminescence images. J. Vis.-Jap. 2008, 11, 329-335. [CrossRef]

50. Huang, S.; Park, H.; Park, Y.K.; Jo, Y.M. Dynamic trajectory and capture of fine dust by magnetic mesh filters based on a particle velocity model. Aerosol Sci. Technol. 2015, 49, 633-642. [CrossRef]

51. ABAQUS User's Manual; Version 6.14; ABAQUS Inc.: Palo Alto, CA, USA, 2014.

52. Wang, Y.Y.; Lu, C.; Li, J.; Tan, X.M.; Tse, Y.C. Simulation of drop/impact reliability for electronic devices. Finite Elem. Anal. Des. 2005, 41, 667-680. [CrossRef]

53. Zukas, J.A.; Scheffler, D.R. Impact effects in multilayered plates. Int. J. Solids. Struct. 2001, 38, 3321-3328. [CrossRef]

54. Wang, L.; Shang, Z.; Shi, M.; Cao, P.; Yang, B.; Zou, J. Preparing and testing the reliability of long-afterglow $\mathrm{SrAl}_{2} \mathrm{O}_{4}: \mathrm{Eu}^{2+}, \mathrm{Dy}^{3+}$ phosphor flexible films for temperature sensing. RSC Adv. 2020, 10, 11418-11425. [CrossRef]

55. Guo, C.; Luan, L.; Huang, D.; Su, Q.; Lv, Y. Study on the stability of phosphor $\mathrm{SrAl}_{2} \mathrm{O}_{4}: \mathrm{Eu}^{2+}$, $\mathrm{Dy}^{3+}$ in water and method to improve its moisture resistance. Mater. Chem. Phys. 2007, 106, 268-272. [CrossRef]

56. Midha, V.K.; Dakuri, A.; Midha, V. Studies on the properties of nonwoven surgical gowns. J. Ind. Text. 2013, 43, 174-190. [CrossRef]

57. Anatoly, C.; Pavel, Z.; Tatiana, C.; Alexei, R.; Svetlana, Z. Water vapor permeability through porous polymeric membranes with various hydrophilicity as synthetic and natural barriers. Polymers 2020, 12, 282. [CrossRef]

58. Wang, C.; Lai, P.-C.; Syu, S.H.; Leu, J. Effects of $\mathrm{CF}_{4}$ plasma treatment on the moisture uptake, diffusion, and WVTR of poly(ethylene terephthalate) flexible films. Surf. Coat. Technol. 2011, 206, 318-324. [CrossRef]

(C) 2020 by the authors. Licensee MDPI, Basel, Switzerland. This article is an open access article distributed under the terms and conditions of the Creative Commons Attribution (CC BY) license (http://creativecommons.org/licenses/by/4.0/). 